\title{
Article \\ Effects of Live Music Therapy on Autonomic Stability in Preterm Infants: A Cluster-Randomized Controlled Trial
}

\author{
Dana Yakobson ${ }^{1,2, *(D)}$, Christian Gold ${ }^{3,4}{ }^{(D}$, Bolette Daniels Beck ${ }^{1}$, Cochavit Elefant ${ }^{5}$, Sofia Bauer-Rusek ${ }^{2,6}$ \\ and Shmuel Arnon 2,6
}

check for

updates

Citation: Yakobson, D.; Gold, C.; Beck, B.D.; Elefant, C.; Bauer-Rusek S.; Arnon, S. Effects of Live Music Therapy on Autonomic Stability in Preterm Infants: A Cluster-

Randomized Controlled Trial. Children 2021, 8, 1077. https:// doi.org/10.3390/children8111077

Academic Editors: Fabia Franco, Mirco Fasolo, Manuela Filippa and Pierre Kuhn

Received: 26 October 2021

Accepted: 17 November 2021

Published: 22 November 2021

Publisher's Note: MDPI stays neutral with regard to jurisdictional claims in published maps and institutional affiliations.

Copyright: (c) 2021 by the authors. Licensee MDPI, Basel, Switzerland. This article is an open access article distributed under the terms and conditions of the Creative Commons Attribution (CC BY) license (https:// creativecommons.org/licenses/by/ $4.0 /)$
1 Music Therapy Department, Institute for Communication and Psychology, Aalborg University, 9000 Aalborg, Denmark; bolette@hum.aau.dk

2 Neonatal Department, Meir Medical Center, Kfar Saba 44281, Israel; Bauers@clalit.org.il (S.B.-R.); shmuelar@clalit.org.il (S.A.)

NORCE Norwegian Research Centre AS, 5008 Bergen, Norway; chgo@norceresearch.no

4 Department of Clinical and Health Psychology, University of Vienna, 1010 Vienna, Austria

5 School for Creative Arts Therapies, University of Haifa, Haifa 3498838, Israel; celefant@univ.haifa.ac.il

Sackler Faculty of Medicine, Tel Aviv University, Tel Aviv 6997801, Israel

* Correspondence: dyakobson@hum.aau.dk; Tel.: +97-2507767782

\begin{abstract}
Unbuffered stress levels may negatively influence preterm-infants' autonomic nervous system (ANS) maturation, thus affecting neurobehavior and psycho-emotional development. Music therapy (MT) is an evidence-based treatment modality in neonatal care. When coupled with skinto-skin care (SSC), it may reduce stress responses in both preterm infants and their parents and enhance family-centered care. Accordingly, we aimed to compare the effects of combined MT and SSC and SSC alone on ANS stabilization in preterm infants. In a single-center, cluster-randomized trial design, ten two-month time-clusters were randomized to either combined MT and SSC or SSC alone. Families of preterm infants were offered two sessions of the allocated condition in the NICU, and a three-month follow up session at home. The primary outcome variable was stabilization of the ANS, defined by change in the high frequency (HF) power of heart rate variability (HRV) during the second session. Secondary outcomes included other HRV measures, parent-infant attachment, and parental anxiety at each session. Sixty-eight families were included. MT combined with SSC improved infants' ANS stability, as indicated by a greater increase in HF power during MT compared to SSC alone (mean difference $5.19 \mathrm{~m}^{2} / \mathrm{Hz}, \mathrm{SE}=1.27, p<0.001$ ) (95\% confidence interval 0.87 to 2.05). Most secondary outcomes were not significantly different between the study groups. MT contributes to preterm-infants' autonomic stability, thus laying an important foundation for neuro-behavioral and psycho-emotional development. Studies evaluating longer-term effects of MT on preterm infants' development are warranted.
\end{abstract}

Keywords: music therapy; preterm infants; family-centered care; autonomic stability; heart rate variability

\section{Introduction}

Neonatal stress exposure is common treating premature infants. The intense medical care, stimulating neonatal intensive care unit (NICU) environment, and parental separation are all major contributors to preterm infants' stress experiences [1], leading to over stimulation during a critical period of neurodevelopment [2]. Preterm infants' autonomic nervous system (ANS) is highly vulnerable due to immaturity and neuroplasticity [3], and is chronically triggered with repeated fight-or-flight reactions to the external stressors. Disruption of the ANS maturation may lead to an allostatic load [4], diminish their ability to cope, and harm synaptogenesis development and neurodevelopmental outcomes [5,6]. Simultaneously, the preterm-birth and NICU conditions may lead parents to experience posttraumatic stress, anxiety, and depression [7], which affect parent-infant bonding processes and further impact infants' developmental outcomes [1]. 
Combined skin-to-skin care (SSC) and music therapy (MT) may promote autonomic and physiologic stabilization in preterm infants [8], reduce stress in parents [9], and further contribute to their ability to handle the stressful effects of the NICU conditions. As SSC is the main form of physical bonding between preterm infants and their parents in the NICU [10], transmitting the parental voice or music listening during SCC may consider multi-sensory precautions and promote family-centered care [11]. This type of multimodal intervention may have an additive beneficial affect for preterm infants [12] However, combined MT and SSC have been investigated in only few, under-powered studies [13-16]. One study demonstrated that maternal singing during SSC significantly improved preterm-infants' autonomic stability and maternal anxiety compared to SSC alone [17], although without giving therapeutic support to the parent-infant dyad. Forming intimacy and meaningful interactions in the high-tech medical NICU environment may be challenging $[18,19]$. Support from a professional NICU music therapist during SSC may enhance these early bonding experiences and improve infants' ANS regulation by providing an informed sensitivity to infants' communication cues, parental needs, and modifying their physical sound environment [20].

There is a paucity of neonatal MT trials examining sensitive physiological markers such as heart rate variability [21], which is recognized as an important indicator of ANS maturation [22]. Furthermore, a recent meta-analysis [9] and two systematic reviews [21,23] highlighted the lack of rigor in MT trials within a family-centered approach facilitated by a certified NICU music therapist, and long-term outcomes. Accordingly, we aimed to examine the effects of a family-centered MT intervention during SSC. We conducted a cluster-randomized controlled trial (cRCT), to compare the effects of combined familycentered MT and SSC and SSC alone, on preterm-infants' autonomic stability and parental wellbeing during the NICU admission and at three-month follow-up. Our hypothesis was that combined MT and SSC, as compared to SSC alone, would enhance better ANS regulation, decrease parental stress, and increase parent-to-infant attachment.

\section{Materials and Methods}

\subsection{Design}

In this single center cRCT with two parallel arms, 10 time-clusters of two months each were allocated to either combined MT and SSC or SSC alone. Constrained randomization of pairwise matching clusters was conducted by an external researcher with no contact with participants (C.G.). The time-clusters design was chosen to prevent the high potential of contamination bias between groups due to the open bay setting of the participating NICU. Each time cluster lasted for two months, corresponding to the average length of stay for infants in the participating NICU, namely, six weeks. In each time-cluster, all parentinfant dyads (mother-infant or father-infant, separately) participated in two sessions of the assigned intervention, and in a three-month follow-up session at home.

\subsection{Setting and Procedures}

Sessions lasted 30-45 min. Recommended sound volumes of an hourly Leq of $50 \mathrm{~dB}$ [24] were monitored using a sound analyzer (Extech SL130, Extech Instruments, Nashua, NH, USA). Normothermia in infants was controlled by a temperature probe for continuous monitoring. The study was conducted in the NICU at Meir Medical Center in Kfar Saba, Israel, a 24-bed, level III, tertiary NICU with Newborn Individualized Developmental Care and Assessment Program (NIDCAP) certification. Screening, recruitment, and informed consent were conducted by the senior neonatologist (S.A.) and a NIDCAP trainer. The trial was prospectively registered in ClinicalTrials.gov, NCT03023267, and the full trial protocol was published [25]. 


\subsection{Participants}

All clinically stable preterm infants with gestational age (GA) $<36$ weeks and confirmed hearing based on otoacoustic emissions tests were eligible. The hearing test was conducted prior to study entry by a specialized assessor at the NICU environment. Clinical stability was assessed by the senior neonatologist and included no mechanical ventilation or acute illness. Severity of prematurity was categorized according to the neonatal medical index [26]. All parents with sufficient understanding of the study language were eligible. Infants were excluded due to medications acting on the central nervous system, any respiratory distress with oxygen support, intraventricular hemorrhage stage $\geq 3$, periventricular leukomalacia, active apnea episodes who require medical intervention, or an estimated hospitalization of less than ten days. Additionally, pre-study data were collected from medical charts and included bronchopulmonary dysplasia, necrotizing enterocolitis, respiratory distress syndrome, retinopathy of prematurity, and sepsis episodes. Parents with language or cognitive difficulty preventing compliance with study procedures were excluded.

\subsection{Clusters Randomization and Recruitment}

Between May 2017 and September 2018, 10 clusters were randomized. This comprised five in each arm, including 68 eligible families who consented and were enrolled. The intraclass coefficient (ICC) was $5 \%$, indicating a moderate effect of the clustering. Baseline characteristics of 68 infants (MT: $N=37$, SSC: $N=31$ ), and 79 parents (MT: $N=42$, SSC: $N=37$ ) were similar across the two arms (Table 1), indicating that the cluster randomization achieved baseline balance. Infants' mean gestational age was $30.56 \pm 2.66$ and $31.06 \pm 2.92$ weeks (in MT and SSC groups, respectively). In both groups, 75\% of the dyads completed at least three sessions. In most families only one parent participated, usually the mother $(N=47 / 68$ infants, $72 \%)$.

Table 1. Baseline characteristics.

\begin{tabular}{|c|c|c|c|}
\hline Characteristics & $\mathrm{MT}+\mathrm{SSC}$ & SSC & $p$-Value ${ }^{a}$ \\
\hline Neonatal & $N=37$ & $N=31$ & \\
\hline Gestational age, wk ${ }^{b}$ & $30.56 \pm 2.66$ & $31.06 \pm 2.92$ & 0.47 \\
\hline Birth weight, $\mathrm{g}$ & $1474.86 \pm 494.00$ & $1492.84 \pm 460.10$ & 0.88 \\
\hline Age at study entry, $\mathrm{d}^{\mathrm{b}}$ & $29.08 \pm 24.44$ & $24.19 \pm 16.93$ & 0.34 \\
\hline Age at study entry, wk ${ }^{b}$ & $34.74 \pm 1.92$ & $34.45 \pm 1.70$ & 0.54 \\
\hline Male sex ${ }^{c}$ & $15(40 \%)$ & $18(58 \%)$ & 0.15 \\
\hline $\begin{array}{c}\text { Neonatal medical } \\
\text { index grade } \\
1 / 2 / 3^{c}\end{array}$ & $\begin{array}{c}11(30 \%) / 20(54 \%) / \\
4(12 \%)\end{array}$ & $\begin{array}{c}12(39 \%) / 13(42 \%) / \\
6(19 \%)\end{array}$ & 0.33 \\
\hline $\begin{array}{c}\text { AGA/SGA }{ }^{c} \\
\text { Ethnic Origin }^{c}\end{array}$ & $31(84 \%) / 5(13 \%)$ & $24(77 \%) / 7(23 \%)$ & 0.43 \\
\hline Jewish/Arab & $35(95 \%) / 2(5 \%)$ & $28(90 \%) / 3(10 \%)$ & 0.50 \\
\hline Parental & $N=42$ & $N=37$ & \\
\hline Female sex ${ }^{c}$ & $30(71 \%)$ & $27(73 \%)$ & \\
\hline $\begin{array}{l}\text { Participation of one parent/ } \\
\text { Both parents }{ }^{\mathrm{c}}\end{array}$ & $28(76 \%) / 9(24 \%)$ & $26(84 \%) / 5(16 \%)$ & 0.40 \\
\hline
\end{tabular}

Abbreviations: MT, music therapy; SSC, skin-to-skin care; AGA/SGA—appropriate/ small for gestational age ${ }^{a}$ equal variances not assumed; independent-sample $t$-tests were used for continuous variables and Pearson Chi-squared tests for categorical variables; ${ }^{\mathrm{b}}$ Mean $\pm \mathrm{SD} ;{ }^{\mathrm{c}} n(\%)$.

\subsection{Interventions}

Experimental group: Family-centered MT during SSC (hereafter, referred to as MT). The intervention was based on the "First Sounds: Rhythm, Breath and Lullaby" (RBL) model [27], and facilitated by a certified RBL-music therapist (D.Y.). After SSC placement, parents were instructed to entrain their breathing patterns to their infants' respiratory rates, and by doing so, to gradually stabilize both. The music therapist accompanied them using the Remo Ocean disk, an instrument especially designed to promote breathing and relaxation by resembling the intrauterine sound environment [28]. Parents were then 
guided to hum in repeated, simple, melodic patterns. The humming gradually developed to singing two to three songs of the parents' choice, adapted to a lullaby rhythm (i.e., "song of kin" [29]). These songs were accompanied by guitar music according to parents" preferences. The intervention guidelines [25] allowed for flexibility to address alternating parental or infants' needs. Some parents asked for vocal or instrumental support prior to taking the active role and singing or preferred to receptively listen to their songs played live by the music therapist. In any case, they were encouraged to softly talk to their infant, tell a story or share their emotional experiences.

Control group: SSC alone (hereafter referred to as SSC), as described previously [30]. SSC practice is considered standard care in the participating NICU. Parents were guided to act as they usually would during SSC time, with the restriction of singing. No therapeutic conversation was offered. Infants were monitored through all sessions by a trained research assistant. The intervention was paused at any sign of stress and was treated by the infants nurse. Further details of both interventions are described in the protocol [25].

\subsection{Outcomes}

Primary outcome: Stabilization of the autonomic nervous system (ANS) and reduced stress in preterm infants, as indicated by a change in the high frequency (HF) power of their heart rate variability (HRV). We examined the HF change during the second session (i.e., from the first to the last part of the session). The first intervention session was considered more preparatory, and so we decided to focus on the second session assuming by then parents would have been familiarized with the process. HRV is the spontaneous beat-to-beat variations in heart rate. These variations originate from the autonomic nervous system (ANS) and provide information about its parasympathetic and sympathetic branches [31]. It is measured through spectral power analysis of its high and low frequency (HF, LF) domains. The HF band at $0.15-1.8 \mathrm{~Hz}$ is considered to reflect vagal efficiency in the parasympathetic system, an indicator of rest-and-digest reactions. The LF band at $<0.15 \mathrm{~Hz}$ may indicate sympathetic activity, which occurs during the fight-or-flight reaction, or parasympathetic withdrawal [32]. Accordingly, the LF/HF ratio may reflect the sympatho-vagal balance, a relationship between relaxation and stress [33]. High values of HF and low values of LF and LF/HF ratio are considered signs of ANS stability and low stress [17]. HRV analysis was conducted using the electrocardiogram (ECG) analogue signal from the cardiorespiratory monitor (Philips, Agilent monitors, Irvine, CA, USA) [34] The monitor records infants' heart rate, respiratory rate, and oxygen saturation, as part of their routine care. The ECG analogue signals were recorded continuously during all sessions, from $10 \mathrm{~min}$ before until $10 \mathrm{~min}$ after the end of the session. These records were fed by an external neonatologist into an HRV software program (ANSR1000 system Ansar, Inc., Philadelphia, PA, USA) and converted to digital values, reflecting cyclic changes. The software's algorithm eliminates movements and artifacts and transforms the data into a waveform across a spectrum of frequencies measured in $\mathrm{Hz}$ using the geometric mean.

Secondary outcomes-preterm infants: Change in LF power and LF/HF ratio during the second session, and mean HF, LF, and LF/HF ratio across all three sessions were considered as secondary outcomes. Additional infant outcomes (fine-grained withinsession change) will be reported separately.

Parental outcomes: Parent-to-infant attachment level was measured with the maternal postnatal attachment scale (MPAS) [35]. This validated, 19-item self-report questionnaire is scored on a five-point Likert scale, describing parents' behaviors, attitudes, and feelings towards their baby. Total scores range from 19 to 95, and higher scores represent higher attachment. The MPAS was obtained at study entry, after one month, and in the threemonths follow-up. State anxiety was measured using the State-Trait Anxiety Inventory (STAI) [36]. It includes 20 self-report statements evaluating current anxiety symptoms, scored on a scale from 1 (not at all) to 4 (very much). Scores range from 20 to 80 , where higher scores indicate higher degree of anxiety. The STAI was administered before and after each session. 


\subsection{Power Calculation}

The minimal clinically important difference for HF power in infants is unknown. Accordingly, the power calculation for the primary outcome was informed by a previous study [17], which found a mean value of $16.8 \mathrm{~ms}^{2} / \mathrm{Hz}$ for HF power during combined maternal singing and SSC, as compared to $10.5 \mathrm{~ms}^{2} / \mathrm{Hz}$ during SSC alone (effect size $d=1.44$ ). We hypothesized that in the current study, HF values may increase more, up to $20 \mathrm{~ms}^{2} / \mathrm{Hz}$, due to the family-centered approach. The study was powered to detect a large effect $(d=0.80)$. Considering the clustered nature of the data, intraclass coefficient $($ ICC $)=0.01$, and $20 \%$ attrition, the total required sample size was 58 [25].

\subsection{Data Analysis}

Analysis of all outcomes was based on the intention-to-treat principle using linear mixed effects (LME) models. Descriptive methods were used for baseline characteristics. Normality of continuous data was assessed graphically. Comparison of effects between groups included bivariate tests for continuous variables and Pearson Chi-squared tests for categorical variables. A two-sided, 5\% significance level was set for the primary outcome, and a $1 \%$ level for secondary outcomes. LME models examined changes over time or effects during a session for all repeated-measures variables. Random effects included timecluster and infant (i.e., if more than one parent participated). Repeated effects included the time points and type of therapy. Covariates' examination included infants' sex, GA, postmenstrual age at study entry, birthweight, and neonatal medical index grade. Analyses were conducted using SPSS for Windows, version 14 (IBM Corp., Armonk, NY, USA) and $\mathrm{R}$ version 3.5.0 [37].

\section{Results}

\subsection{Primary Outcome: Change in Infants' HF Power during the Second Session}

MT was associated with greater increase in HF compared to SSC during the second session. In the entire sample, during the second session, HF power of the infants increased by $4.35 \mathrm{~ms}^{2} / \mathrm{Hz}(\mathrm{SE}=0.96, p<0.001)$, where in the MT condition it was further increased by $5.19 \mathrm{~ms}^{2} / \mathrm{Hz}$ (SE $=1.27, p<0.001$; Table 2, Figure 1, panel a). During the entire session, HF values were $2.55 \mathrm{~ms}^{2} / \mathrm{Hz}$ (SE $=0.94, p=0.027$ ) higher in the MT group compared to SSC.

Table 2. Linear mixed effects (LME) model of primary outcome-high-frequency (HF) change in the second session.

\begin{tabular}{ccc}
\hline HF Power Change in Second Session & B (SE) & $p$-Value \\
\hline No. of observations: 124 & $\mathrm{~ms}^{2} / \mathrm{Hz} \mathrm{SD}$ & \\
Intercept $^{\text {a }}$ & $8.55(0.69)$ & $<0.001$ \\
Session part: last & $4.35(0.96)$ & $<0.001$ \\
Parent: father & $-3.36(1.83)$ & 0.068 \\
Treatment: MT + SSC & $2.55(0.94)$ & 0.027 \\
Session part: last X treatment: MT + SSC & $5.19(1.27)$ & $<0.001$ \\
Parent: father X treatment: MT + SSC & $-1.36(2.06)$ & 0.510 \\
\hline
\end{tabular}

Abbreviations: MT, music therapy; SSC, skin-to-skin care. B, beta coefficient; SE, standard error; ${ }^{\text {a }}$ Intercept is the predicted value for mothers in the first part of the second SSC session. 
(a) HF Power (primary outcome)

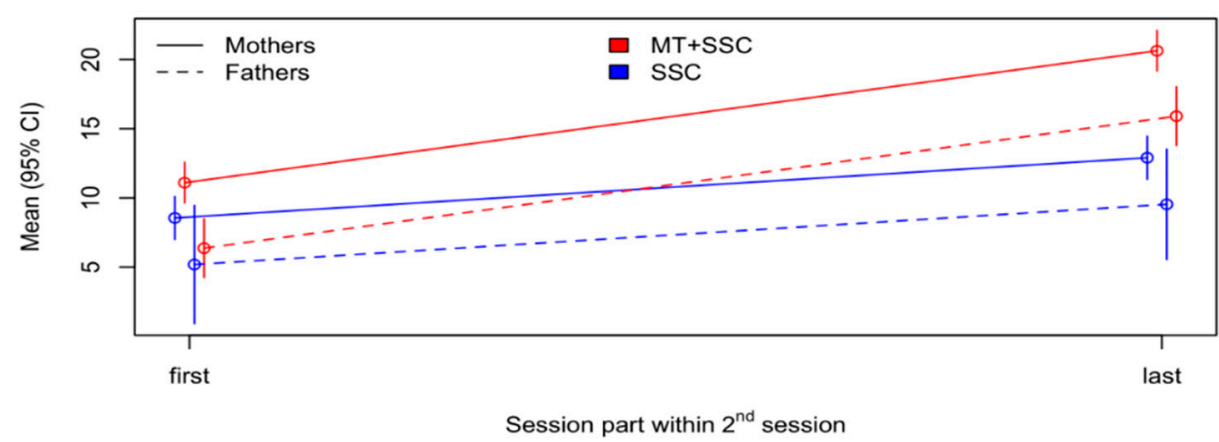

(b) LF Power

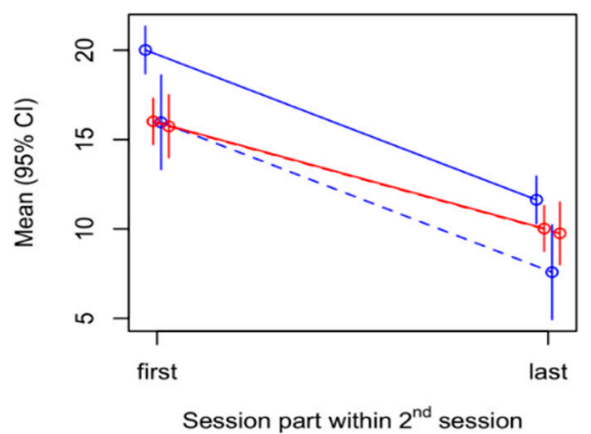

(c) LF/HF Ratio

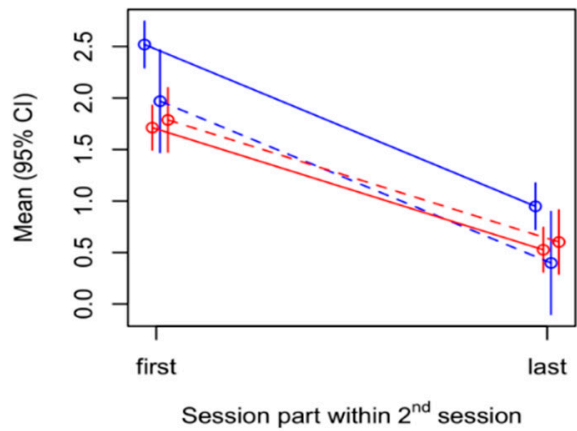

Figure 1. HRV parameters during the second session. (a): Primary outcome-Change in HF parameters during the second session; (b): Change in LF power; (c): Change in LF/HF ratio.

During MT, the observed mean values of HF increased by $9.8 \mathrm{~ms}^{2} / \mathrm{Hz}$ from 9.86 in the first part of session to 19.66 in the last part, compared to a smaller increase of $4.24 \mathrm{~ms}^{2} / \mathrm{Hz}$ from 8.45 to 12.69 during SSC, with between-group effect size during the last part of the session of $\mathrm{d}=1.46(95 \%$ CI 0.87 to 2.05 ; Table 3).

Table 3. Observed values of HRV parameters in the second session.

\begin{tabular}{|c|c|c|c|c|}
\hline HRV Variable & $\mathrm{MT}+\mathrm{SSC}$ & SSC & $p$-Value ${ }^{a}$ & Effect Size (95\% CI) \\
\hline & $\mathrm{ms}^{2} / \mathrm{Hz}(\mathrm{SD})$ & $\mathrm{ms}^{2} / \mathrm{Hz}$ (SD) & & \\
\hline Mean HF, first part & $9.86(2.44)$ & $8.45(2.02)$ & 0.020 & $0.623(0.084,1.156)$ \\
\hline Mean HF, last part & $19.66(6.26)$ & $12.69(1.23)$ & $<0.001$ & $1.461(0.866,2.046)$ \\
\hline Mean LF, first part & $15.88(2.52)$ & $19.88(2.82)$ & $<0.001$ & $-1.501(-2.089,-0.903)$ \\
\hline Mean LF, last part & $9.97(2.10)$ & $11.41(2.45)$ & 0.023 & $-0.635(-1.165,-0.100)$ \\
\hline Mean LF/HF ratio, first part & $1.71(0.57)$ & $2.52(0.66)$ & $<0.001$ & $-1.320(-1.893,-0.736)$ \\
\hline Mean LF/HF ratio, last part & $0.53(0.29)$ & $0.90(0.27)$ & $<0.001$ & $-1.368(-1.945,-0.781)$ \\
\hline
\end{tabular}

Abbreviations: HF, high frequency; LF, low frequency; MT, music therapy; SSC, skin-to-skin care; ${ }^{\text {a }}$ equal variances not assumed; $t$-tests for continuous variables; following intention-to-treat principle.

In an additional analysis of each parent separately, the interaction between session part and treatment type was significant only in mothers (Table S1).

Examination of covariates: Infants' sex, GA, age at study entry, birthweight, and neonatal medical index grade were entered into the LME. None were predictive of HF change or influenced the demonstrated effect of MT (Table S2). 


\subsection{Secondary Outcomes}

\subsubsection{LF Power and LF/HF Ratio in the Second Session}

Results are shown in Table 4, and Figure 1, panels $b$ and c. Infants' LF power decreased during the second session $(\mathrm{B}=-8.38, \mathrm{SE}=0.70, p<0.001)$; was generally lower with fathers than with mothers $(\mathrm{B}=-4.05, \mathrm{SE}=1.13, p<0.001)$; and lower during MT than with SSC $(\mathrm{B}=-4.00, \mathrm{SE}=0.81, p=0.001)$. However, the mean decrease in LF over the session was smaller during MT than SSC by $2.4 \mathrm{~ms}^{2} / \mathrm{Hz}(\mathrm{SE}=0.93, p=0.011)$, with effect size of $\mathrm{d}=-0.635$ (95\% CI: -1.16 to -0.100 ; Table 3$)$. The interaction of parent and treatment type was also significant, with a difference of $3.78 \mathrm{~ms}^{2} / \mathrm{Hz}(\mathrm{SE}=1.34, p=0.006)$.

Table 4. Linear mixed effects models of secondary outcomes in the second session.

\begin{tabular}{ccc}
\hline LF Change in Second Session & B (SE) & $p$-Value \\
\hline No. of observations: 127 & & \\
Intercept $^{\text {a }}$ & $20.01(0.59)$ & $<0.001$ \\
Session part: last & $-8.38(0.70)$ & $<0.001$ \\
Parent: father & $-4.05(1.13)$ & $<0.001$ \\
Treatment: MT + SSC & $-4.00(0.81)$ & 0.001 \\
Session part: last X treatment: MT + SSC & $2.40(0.93)$ & 0.011 \\
Parent: father X treatment: MT + SSC & $3.78(1.34)$ & \\
\hline LF/HF Ratio Change in Second Session & & $<0.001$ \\
\hline No. of observations: 126 & & $<0.001$ \\
Intercept & $2.52(0.10)$ & 0.015 \\
Session part: last & $-1.57(0.14)$ & $<0.001$ \\
Parent: father & $-0.55(0.22)$ & 0.039 \\
Treatment: MT + SSC & $-0.81(0.14)$ & 0.019 \\
\hline Session part: last X treatment: MT + SSC & $0.38(0.18)$ & \\
Parent: father X treatment: MT + SSC & $0.62(0.26)$ & \\
\hline
\end{tabular}

Abbreviations: MT, music therapy; SSC, skin-to-skin care; B, beta coefficient; SE, standard error; ${ }^{\text {a }}$ Intercept is the predicted value for mothers in the first part of the second SSC session.

Infants' LF/HF ratio was also generally decreased during the second session by $-1.57 \mathrm{~ms}^{2} / \mathrm{Hz}(\mathrm{SE}=0.14, p<0.001)$. LF $/ \mathrm{HF}$ ratio was lower with fathers than with mothers $(\mathrm{B}=-0.55, \mathrm{SE}=0.22, p=0.015)$; lower with MT than with SSC $(\mathrm{B}=-0.81$, $\mathrm{SE}=0.14, p<0.001)$; and decreased less during MT than during SSC $(\mathrm{B}=0.38, \mathrm{SE}=0.18$, $p=0.039)$. The observed mean values decreased from 1.71 to 0.53 in MT, compared to a larger decrease from 2.52 to 0.90 in SSC, with effect size of $d=-1.37$ (95\% CI -1.94 to -0.78 ; Table 3).

\subsubsection{HRV Parameters across All Three Sessions}

See Table 5 and Figure 2, panels a-c. The HF power was higher in the second session compared to the first session $(\mathrm{B}=1.16, \mathrm{SE}=0.66, p=0.078)$, and further increased in the third session by $0.83(\mathrm{SE}=0.95)$ in the MT group only. No significant differences were demonstrated.

The LF power decreased from the first to the second session by $-3.24 \mathrm{~ms}^{2} / \mathrm{Hz}$ $(\mathrm{SE}=0.82, p<0.001)$, but increased in the third session by $3.73 \mathrm{~ms}^{2} / \mathrm{Hz}(\mathrm{SE}=0.89, p<0.001)$. $\mathrm{LF}$ was lower in sessions with fathers than with mothers $(\mathrm{B}=-6.62, \mathrm{SE}=0.98, p<0.001)$, and significantly lower in MT in the third session, compared to SSC alone (B $=-2.74$, $\mathrm{SE}=1.20, p=0.023)$. Finally, $\mathrm{LF}$ was higher in sessions with fathers compared to mothers within the MT group $(\mathrm{B}=3.00, \mathrm{SE}=1.27, p=0.020)$.

Similarly, LF/HF ratio decreased from the first to the second session $(\mathrm{B}=-0.38$, $\mathrm{SE}=0.10, p<0.001)$ and increased in the third session $(\mathrm{B}=0.30, \mathrm{SE}=0.11, p=0.008) . \mathrm{LF} / \mathrm{HF}$ ratio was lower with fathers than with mothers $(\mathrm{B}=-0.76, \mathrm{SE}=0.12, p<0.001)$, and was significantly lower in the third session in $\mathrm{MT}(\mathrm{B}=-0.42, \mathrm{SE}=0.15, p=0.006)$. Finally, $\mathrm{LF} / \mathrm{HF}$ ratio was higher in MT sessions with fathers $(\mathrm{B}=0.46, \mathrm{SE}=0.16, p=0.004)$. The observed values of all HRV indices across all sessions are provided in Table S3. 
(a) HF Power

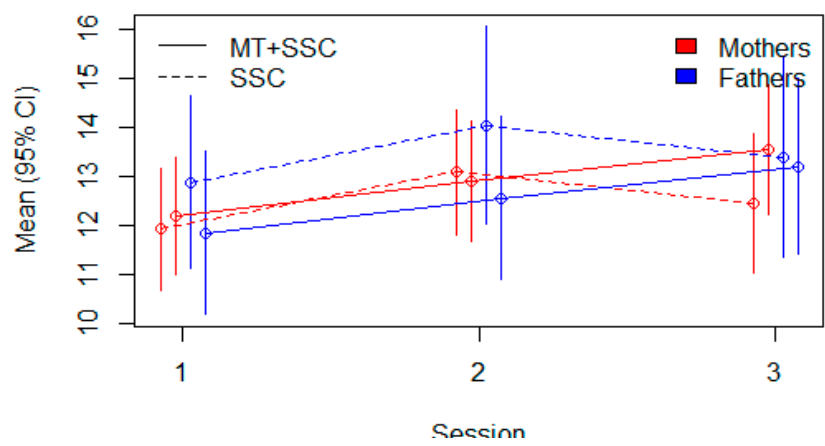

(b) LF Power

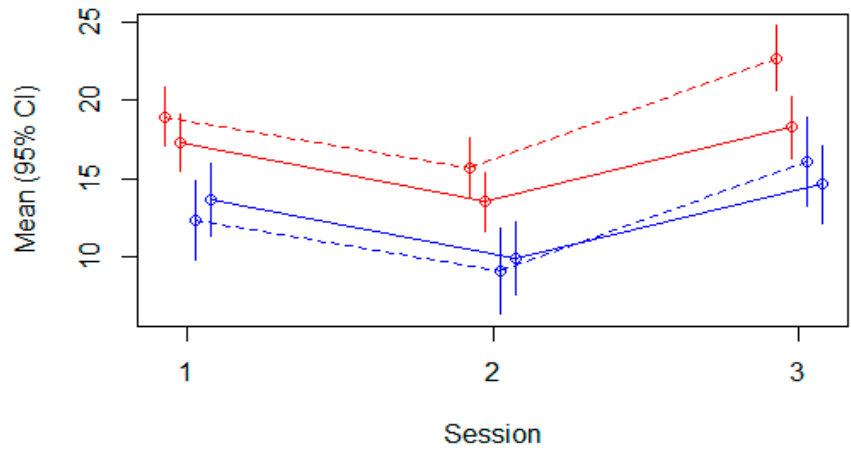

(c) LF/HF Ratio

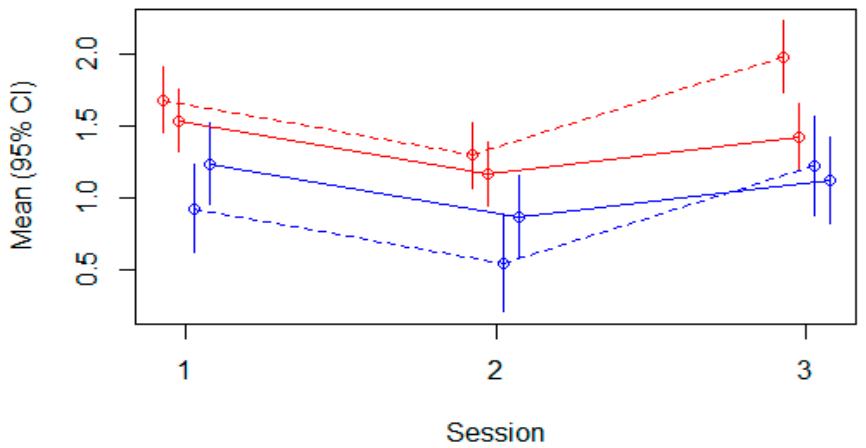

Figure 2. HRV parameters across all three sessions. (a): HF; (b): LF; (c): LF/HF ratio.

Table 5. Linear mixed effects models of secondary HRV outcomes across all three sessions.

\begin{tabular}{ccc}
\hline HF Power across Sessions & B (SE) & $p$-Value \\
\hline No. of observations: 199 & & $<0.001$ \\
Intercept $^{\mathrm{a}}$ & $11.93(0.55)$ & 0.078 \\
Second session & $1.16(0.66)$ & 0.462 \\
Third session & $0.52(0.71)$ & 0.212 \\
Parent: fathers & $0.95(0.76)$ & 0.725 \\
Treatment: MT + SSC & $0.27(0.75)$ & 0.608 \\
Second session X treatment: MT + SSC & $-0.45(0.89)$ & 0.385 \\
Third session X treatment: MT + SSC & $0.83(0.95)$ & 0.194 \\
Parent: fathers X treatment: MT + SSC & $-1.30(0.99)$ &
\end{tabular}


Table 5. Cont.

\begin{tabular}{ccc}
\hline LF Power across Sessions & & \\
\hline No. of observations: 199 & $18.92(0.82)$ & $<0.001$ \\
Intercept & $-3.24(0.82)$ & $<0.001$ \\
Second session & $3.73(0.89)$ & $<0.001$ \\
Third session & $-6.62(0.98)$ & $<0.001$ \\
Parent: fathers & $-1.68(1.13)$ & 0.177 \\
Treatment: MT + SSC & $-0.51(1.11)$ & 0.646 \\
Second session X treatment: MT + SSC & $-2.74(1.20)$ & 0.023 \\
Third session X treatment: MT + SSC & $3.00(1.27)$ & 0.020 \\
Parent: fathers X treatment: MT + SSC & & \\
\hline LF/HF Power across Sessions & & $<0.001$ \\
No. of observations: 198 & $1.68(0.10)$ & $<0.001$ \\
Intercept & $-0.38(0.10)$ & 0.008 \\
Second session & $0.30(0.11)$ & $<0.001$ \\
Third session & $-0.76(0.12)$ & 0.325 \\
Parent: fathers & $-0.14(0.14)$ & 0.897 \\
Treatment: MT + SSC & $0.02(0.14)$ & 0.006 \\
Second session X treatment: MT + SSC & $-0.42(0.15)$ & 0.004 \\
Third session X treatment: MT + SSC & $0.46(0.16)$ & \\
Parent: fathers X treatment: MT + SSC & & \\
\hline
\end{tabular}

Abbreviations: MT, music therapy; SSC, skin-to-skin care. ${ }^{\text {a }}$ Intercept is the predicted value for mothers in the first part of the second SSC session; B, beta coefficient; SE, standard error.

\subsection{Parental Outcomes}

Parent-to-infant attachment scores across the three sessions were smaller by -3.26 $(\mathrm{SE}=1.75)$ points in the MT group compared to SSC $(p=0.100)$. No statistical significance was demonstrated (Table 6). The mean scores in both groups ranged from $72.10(\mathrm{SD}=14.45$, $p=0.741)$ to $81.67(\mathrm{SD}=5.77, p=0.031)$ (Table S4), retaining a moderate-high level of parent-to-infant attachment across all measurements.

Table 6. Linear mixed effects models of parental outcomes across sessions.

\begin{tabular}{ccc}
\hline Maternal Postnatal Attachment Scale & B (SE) & $p$-Value \\
\hline No. of observations: 166 & & $<0.001$ \\
Intercept $^{\text {a }}$ & $81.69(1.31)$ & 0.942 \\
One month assessment & $0.14(2.00)$ & 0.303 \\
Three-month follow-up & $-1.88(1.82)$ & 0.517 \\
Parent: fathers & $-1.37(2.10)$ & 0.100 \\
Treatment: MT + SSC & $-3.26(1.75)$ & 0.709 \\
One month assessment X Treatment: MT + SSC & $-1.11(2.97)$ & 0.219 \\
Three months X treatment: MT + SSC & $2.98(2.41)$ & 0.606 \\
Parent: father X treatment: MT + SSC & $-1.40(2.71)$ & \\
State-Trait Anxiety Inventory & & $<0.001$ \\
No. of observations: 400 & & 0.252 \\
Intercept & $31.53(1.46)$ & 0.024 \\
Second session & $-1.68(1.46)$ & $<0.001$ \\
Third session & $-3.59(1.59)$ & 0.213 \\
Session part: post & $-4.72(1.25)$ & 0.106 \\
Parent: fathers & $2.01(1.61)$ & 0.286 \\
Treatment: MT + SSC & $3.59(1.97)$ & 0.596 \\
\hline Second session X treatment: MT + SSC & $2.11(1.98)$ & 0.102 \\
Third session X treatment: MT + SSC & $-1.12(2.10)$ & 0.218
\end{tabular}

Abbreviations: MT, music therapy; SSC, skin-to-skin care. ${ }^{\text {a }}$ Intercept is the predicted value for mothers in the pre-test, first session in SSC group; B, beta coefficient; SE, standard error. 
Parental state-anxiety levels decreased by $4.72(\mathrm{SE}=1.25)$ points from pre- to post-tests in the entire sample $(p<0.001)$ (Table 6). The MT group showed a nonsignificant tendency for greater decrease in anxiety levels by 3.59 points $(p=0.106)$ across the three sessions, with a further decrease of 2.74 points from pre- to post-measurements, as compared to SSC ( $p=0.218$; Figure 3 ). In both groups, the mean STAI scores at all assessments ranged from $22.85(\mathrm{SD}=3.17, p=0.686)$ to $35.74(\mathrm{SD}=13.62, p=0.184)$, representing normal anxiety levels (Table S4).

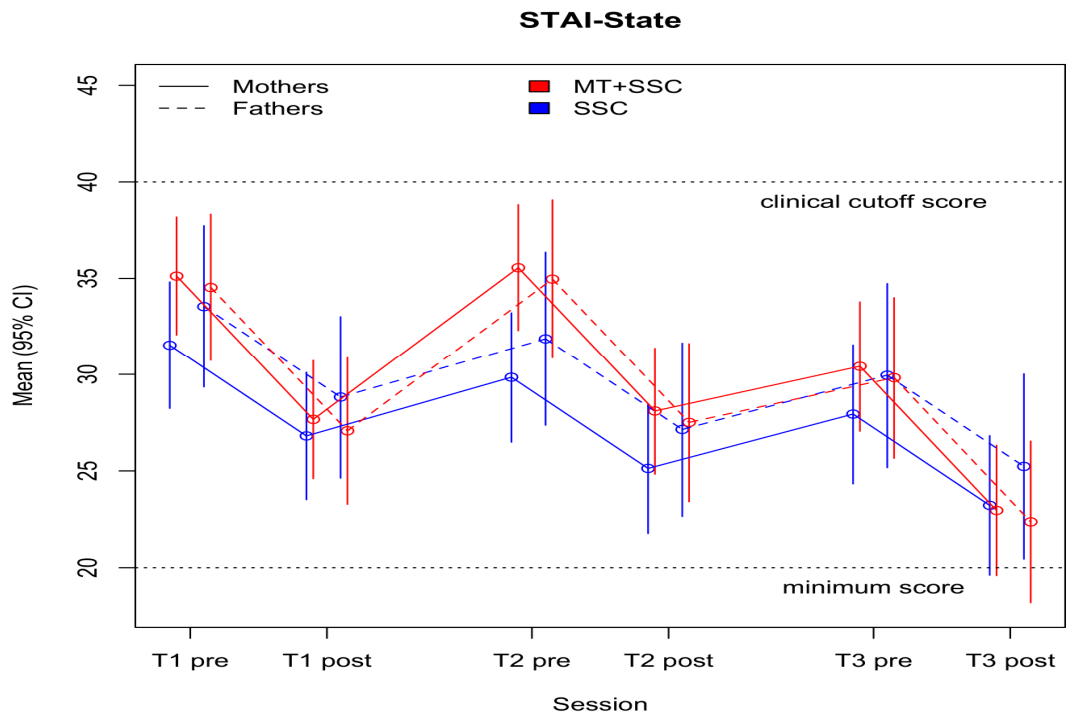

Figure 3. Parental state-anxiety measures across all sessions.

Adverse events: In the SSC group, one infant's participation had to be paused for a week due to recurring need of ventilation. No serious adverse events occurred.

\section{Discussion}

Music therapy added to SSC resulted in improved ANS stability in preterm infants, as was indicated by the significant increase in HF power of their HRV, and higher values of HF during the entire session, compared to SSC alone. These findings support our assumption that during family-centered MT, infants' HF power would reach around $20 \mathrm{~ms}^{2} / \mathrm{Hz}$, thus further extending previous findings regarding the effectiveness of maternal singing during SSC [17]. HF power is an indicator of a relaxed state of the ANS [22,38,39], representing improvement in autonomic regulation, which strongly impacts preterm-infants' processes of recovery and maturation. Elevated neonatal stress exposure may severely harm their ANS development and function [40-42], and negatively affect neurodevelopment and social-emotional participation [6,43]. Alternatively, reduced stress improves autonomic stability [5], and improved autonomic stability increases the infant's ability to handle the external stressors of their environment, thus improving developmental outcomes [43]. Accordingly, an immediate stress-reduction intervention, facilitated by parents, is highly valuable for their developmental outcomes [1]. No significant differences between mothers and fathers were indicated, possibly due to the much smaller sample size of fathers.

During both parts of session 2, LF and LF/HF ratio values were significantly lower in the MT group compared to SSC alone. In both groups, these values decreased significantly by the end of session, suggesting that the effect of time spent in SSC was stronger than treatment type. This pattern of improved stabilization during the session was also seen in the HF analysis, and may be related to the preceding effect of SSC on improvement of HRV parameters [8,44]. However, the smaller change in LF activity in the MT group and the respective bigger change in LF activity in the SSC group cohere with the higher activity of HF that was demonstrated in the MT group and the lower HF activity that was 
demonstrates in the SSC group. Furthermore, the interpretation of LF power and thus $\mathrm{LF} / \mathrm{HF}$ ratio may not be purely indexed as sympathetic activity, in the same way that HF was strongly correlated to parasympathetic activity in the ANS; rather, as described by Billman [45] it may represent "a complex and not easily discernible mix of sympathetic, parasympathetic, and other unidentified factors with parasympathetic factors accounting for the largest portion of the variability in this frequency range. As a consequence, the physiological basis for LF/HF is difficult to discern." Nevertheless, at the three-month follow-up, the effect of MT was clear. HF power had increased from the second to third session only in the MT group, and LF and LF/HF values were significantly lower in the MT group. In both groups, LF and LF/HF ratio values were higher, compared to the NICU sessions. This finding is congruent with a previous study that stated that the ANS in preterm infants stabilizes during the first few months [46].

Parental STAI evaluations showed a trend toward a larger decrease in the MT group. However, parents' mean STAI scores were below the clinical cutoff of 39-40 at all assessments [47], which may have impeded our ability to find effects on anxiety. Similarly, the MPAS did not yield any significant group differences. This questionnaire may not have been suited to the short-term intervention that was offered.

\section{Strengths and Limitations}

The relatively small number of sessions may have influenced our ability to test therapeutic processes [48], as seen in the lack of change in parental outcomes in both groups. Validated clinical cut-offs were not available for all measured outcomes, making clinical interpretation difficult. Outcome assessors were not blinded; however, the primary outcome was based on objective measurements. Furthermore, HRV data were preprocessed by an external researcher not involved in the study. Therefore, the effect on the primary outcome appears to be robust. The broad inclusion criteria, use of the principles of the worldwide RBL model [25], and the setting of the participating NICU, including shared-space accommodations and international family-centered care principles [49], further contribute to the generalizability of the study results.

The present study provided only immediate and short-term results of HRV indexes at around 34 weeks postnatal age during NICU admission period and at three-months corrected age. Further studies evaluating long-term effects of MT on preterm-infants' ANS stabilization and neurobehavioral development are warranted. As HRV power correlates with increased age and ANS maturation [22], future studies may further clarify this process using stratified analysis on preterm infants of different gestational ages and days, to study the correlation between different gestational ages and days and HRV indexes. Additionally, to deepen the understanding of the effects of MT on ANS stabilization in newborns, further studies comparing preterm and full-term infants are warranted.

Finally, the preceding beneficial effects of SSC alone on ANS stability in preterm infants $[8,38,39,44,50]$ may have reduced the observed effects of MT. However, the clinical experience in this NIDCAP certified NICU, as well as the results of the present study, suggest that implementing MT during SSC successfully involves all relevant aspects of protective, multi-sensory family-centered care. Furthermore, SSC position is a clear, protocolized condition, which enabled the comparison between groups much more clearly (in contrast to having the MT intervention during other holding positions).

\section{Conclusions}

Increased HRV, and specifically HF-HRV power, indicate preterm infants' ANS stability and ability to modulate stress, where decreased HRV can be correlated with pathological conditions [51]. According to the neurovisceral integration model, HRV analysis provides a unique insight to brain activity and the heart-brain connection, as it indexes the cardiac vagal tone, and may reflect the functionality of neural networks that are implicated in regulation of physiological, affective, and cognitive processes [52]. This study demonstrated that a family-centered MT intervention during SSC led to an increased HF-HRV power. 
Accordingly, combined MT and SSC can be suggested as an important intervention in the routine care of preterm infants, by contributing to their ANS stability.

Supplementary Materials: The following are available online at https://www.mdpi.com/article/ 10.3390/children8111077/s1, Table S1: Primary outcome: Change in HF power within the second session, mothers, and fathers separately, Table S2: Primary outcome: Covariate examination, Table S3: Observed values of HRV parameters in all three sessions, Table S4: Observed values of parental scores.

Author Contributions: Conceptualization, D.Y., C.G., B.D.B., C.E. and S.A.; methodology, D.Y., C.G., B.D.B., C.E., S.B.-R. and S.A.; software, C.G; validation, C.G., S.A. and S.B.-R.; formal analysis, C.G. and D.Y.; investigation, D.Y. and S.A.; resources, C.G. and S.A.; data curation, D.Y., C.G. and S.A.; writing—original draft preparation, D.Y.; writing—review and editing, D.Y, C.G., B.D.B., C.E., S.B.-R. and S.A.; visualization, D.Y. and C.G.; supervision, C.G., B.D.B. and C.E.; project administration, D.Y. and S.A.; funding acquisition, D.Y., C.E. and C.G. All authors have read and agreed to the published version of the manuscript.

Funding: The study received seed funding from the research committee at the Faculty of Social Welfare \& Health Sciences, University of Haifa, Israel. D.Y. received a doctoral grant from the Department of Communication and Psychology at the Faculty of Humanities, Aalborg University, Denmark. C.G. was partly supported by a grant from the Research Council of Norway (grant number 273534).

Institutional Review Board Statement: The study was conducted according to the guidelines of the Declaration of Helsinki and approved by the Institutional Review Board of MEIR medical center (ethical approval no.0283-15) in April 2017.

Informed Consent Statement: Informed consent was obtained from all subjects involved in the study.

Data Availability Statement: The data presented in this study are available on request from the corresponding author.

Conflicts of Interest: The authors declare no conflict of interest. The funders had no role in the design of the study; in the collection, analyses, or interpretation of data; in the writing of the manuscript, or in the decision to publish the results.

\section{References}

1. Browne, J.V. Infant mental health in intensive care: Laying a foundation for social, emotional and mental health outcomes through regulation, relationships and reflection. J. Neonatal. Nurs. 2021, 27, 33-39. [CrossRef]

2. Als, H.; Duffy, F.H.; McAnulty, G.B.; Rivkin, M.J.; Vajapeyam, S.; Mulkern, R.V.; Warfield, S.K.; Huppi, P.S.; Butler, S.C.; Conneman, N.; et al. Early experience alters brain function and structure. Pediatrics 2004, 113, 846-857. [CrossRef]

3. Gui, L.; Loukas, S.; Lazeyras, F.; Hüppi, P.S.; Meskaldji, D.E.; Borradori Tolsa, C. Longitudinal study of neonatal brain tissue volumes in preterm infants and their ability to predict neurodevelopmental outcome. Neuroimage 2019, 185, 728-741. [CrossRef] [PubMed]

4. Moore, T.A.; Berger, A.M.; Wilson, M.E. A New Way of Thinking About Complications of Prematurity. Biol. Res. Nurs. 2014, 16, 72-82. [CrossRef] [PubMed]

5. Nist, M.D.; Harrison, T.M.; Steward, D.K. The biological embedding of neonatal stress exposure: A conceptual model describing the mechanisms of stress-induced neurodevelopmental impairment in preterm infants. Res. Nurs. Health 2019, 42, 61-71. [CrossRef] [PubMed]

6. Graven, S.N.; Browne, J.V. Sensory Development in the Fetus, Neonate, and Infant: Introduction and Overview. Newborn Infant Nurs. Rev. 2008, 8, 169-172. [CrossRef]

7. Barthel, D.; Göbel, A.; Barkmann, C.; Helle, N.; Bindt, C. Does Birth-Related Trauma Last? Prevalence and Risk Factors for Posttraumatic Stress in Mothers and Fathers of VLBW Preterm and Term Born Children 5 Years After Birth. Front. Psychiatry 2020, 11, 1466. [CrossRef]

8. Feldman, R.; Eidelman, A.I. Skin-to-skin contact (Kangaroo Care) accelerates autonomic and neurobehavioural maturation in preterm infants. Dev. Med. Child Neurol. 2003, 45, 274-281. [CrossRef]

9. Bieleninik, Ł.; Ghetti, C.; Gold, C. Music therapy for preterm infants and their parents: A meta-analysis. Pediatrics 2016, 138. [CrossRef]

10. Bergman, N.; Carney, G.; Ludington-Hoe, S.M. Kangaroo Care for the Preterm Infant. ICAN Infant Child Adolesc. Nutr. 2010, 2, 165-169. [CrossRef] 
11. Haslbeck, F.; Hugoson, P. Sounding Together: Family-Centered Music Therapy as Facilitator for Parental Singing During Skin-toSkin Contact. In Early Vocal Contact and Preterm Infant Brain Development: Bridging the Gaps Between Research and Practice; Springer: Cham, Switzerland; Zurich, Switzerland, 2017; pp. 217-238. ISBN 978-3-319-65075-3.

12. Pineda, R.; Guth, R.; Herring, A.; Reynolds, L.; Oberle, S.; Smith, J. Enhancing sensory experiences for very preterm infants in the NICU: An integrative review. J. Perinatol. 2017, 37, 323-332. [CrossRef] [PubMed]

13. Ettenberger, M.; Rojas Cárdenas, C.; Parker, M.; Odell-Miller, H. Family-centred music therapy with preterm infants and their parents in the Neonatal Intensive Care Unit (NICU) in Colombia-A mixed-methods study. Nord. J. Music Ther. 2017, 26, 207-234. [CrossRef]

14. Teckenberg-Jansson, P.; Huotilainen, M.; Pölkki, T.; Lipsanend, J.; Järvenpääe, A.L. Rapid effects of neonatal music therapy combined with kangaroo care on prematurely-born infants. Nord. J. Music Ther. 2011, 20, 22-42. [CrossRef]

15. Epstein, S.; Bauer, S.; Levkovitz Stern, O.; Litmanovitz, I.; Elefant, C.; Yakobson, D.; Arnon, S. Preterm infants with severe brain injury demonstrate unstable physiological responses during maternal singing with music therapy: A randomized controlled study. Eur. J. Pediatr. 2020. [CrossRef] [PubMed]

16. Kostilainen, K.; Mikkola, K.; Erkkilä, J.; Huotilainen, M. Effects of maternal singing during kangaroo care on maternal anxiety, wellbeing, and mother-infant relationship after preterm birth: A mixed methods study. Nord. J. Music Ther. 2020, 1-20. [CrossRef]

17. Arnon, S.; Diamant, C.; Bauer, S.; Regev, R.; Sirota, G.; Litmanovitz, I. Maternal singing during kangaroo care led to autonomic stability in preterm infants and reduced maternal anxiety. Acta Paediatr. Int. J. Paediatr. 2014, 103, 1039-1044. [CrossRef] [PubMed]

18. Flacking, R.; Thomson, G.; Axelin, A. Pathways to emotional closeness in neonatal units-a cross-national qualitative study. BMC Pregnancy Childbirth 2016, 16, 1-8. [CrossRef] [PubMed]

19. Flacking, R.; Lehtonen, L.; Thomson, G.; Axelin, A.; Ahlqvist, S.; Moran, V.H.; Ewald, U.; Dykes, F. Closeness and separation in neonatal intensive care. Acta Paediatr. 2012, 101, 1032-1037. [CrossRef]

20. Loewy, J.; Jaschke, A.C. Mechanisms of Timing, Timbre, Repertoire, and Entrainment in Neuroplasticity: Mutual Interplay in Neonatal Development. Front. Integr. Neurosci. 2020, 14, 8. [CrossRef]

21. Foroushani, S.M.; Herman, C.A.; Wiseman, C.A.; Anthony, C.M.; Drury, S.S.; Howell, M.P. Evaluating physiologic outcomes of music interventions in the neonatal intensive care unit: A systematic review. J. Perinatol. 2020, 40, 1770-1779. [CrossRef]

22. Longin, E.; Gerstner, T.; Schaible, T.; Lenz, T.; König, S. Maturation of the autonomic nervous system: Differences in heart rate variability in premature vs. term infants. J. Perinat. Med. 2006, 34, 303-308. [CrossRef]

23. Yue, W.; Han, X.; Luo, J.; Zeng, Z.; Yang, M. Effect of music therapy on preterm infants in neonatal intensive care unit: Systematic review and meta-analysis of randomized controlled trials. J. Adv. Nurs. 2020, 1-18. [CrossRef] [PubMed]

24. Graven, S.N. Sound and the Developing Infant in the NICU: Conclusions and Recommendations for Care. J. Perinatol. 2000, 20, S88-S93. [CrossRef] [PubMed]

25. Yakobson, D.; Arnon, S.; Gold, C.; Elefant, C.; Litmanovitz, I.; Beck, B.D. Music Therapy for Preterm Infants and Their Parents: A Cluster-Randomized Controlled Trial Protocol. J. Music Ther. 2020, 57, 219-242. [CrossRef] [PubMed]

26. Korner, A.F.; Stevenson, D.K.; Forrest, T.; Constantinou, J.C.; Dimiceli, S.; Brown, B.W.M. Preterm medical complications differentially affect neurobehavioral functions: Results from a new neonatal medical index. Infant Behav. Dev. 1994, 17, 37-43. [CrossRef]

27. Loewy, J.; Stewart, K.; Dassler, A.M.; Telsey, A.; Homel, P. The effects of music therapy on vital signs, feeding, and sleep in premature infants. Pediatrics 2013, 131, 902-918. [CrossRef]

28. Lullaby Ocean Disc. Available online: https://remo.com/products/product/ocean-disk/ (accessed on 17 June 2021).

29. Loewy, J. NICU music therapy: Song of kin as critical lullaby in research and practice. Ann. N. Y. Acad. Sci. 2015, 1337, 178-185. [CrossRef]

30. Jefferies, A.L.; Canadian Paediatric Society, F. and N.C. and N.C. Kangaroo care for the preterm infant and family. Paediatr. Child Health 2012, 17, 141-146. [CrossRef]

31. Cowan, M.J. Measurement of Heart Rate Variability. West. J. Nurs. Res. 1995, 17, 32-48. [CrossRef]

32. Task Force of the European Society of Cardiology and the North American Society of Pacing and Electrophysiology. Circulation 1996, 93, 1043-1065. [CrossRef]

33. Pagani, M.; Lombardi, F.; Guzzetti, S.; Rimoldi, O.; Furlan, R.; Pizzinelli, P.; Sandrone, G.; Malfatto, G.; Dell'Orto, S.; Piccaluga, E. Power spectral analysis of heart rate and arterial pressure variabilities as a marker of sympatho-vagal interaction in man and conscious dog. Circ. Res. 1986, 59, 178-193. [CrossRef]

34. Philips Patient Monitoring in Irvine California-USOC Medical. Available online: https://usocmedical.com/product-category/ patient-monitoring/philips-patient-monitoring/ (accessed on 17 June 2021).

35. Condon, J.T.; Corkindale, C.J. The assessment of parent-to-infant attachment: Development of a self-report questionnaire instrument. J. Reprod. Infant Psychol. 1998, 16, 57-76. [CrossRef]

36. Spielberger, C.; Gorsuch, R.; Lushene, R.; Vagg, P.R.; Jacobs, G. Manual for the State-Trait Anxiety Inventory (Form Y1-Y2); Consulting Psychologists Press: Santa Clara, CA, USA, 1983; Volume 4.

37. R: The R Project for Statistical Computing. Available online: https:/ / www.r-project.org/ (accessed on 17 June 2021).

38. Butruille, L.; Blouin, A.; De Jonckheere, J.; Mur, S.; Margez, T.; Rakza, T.; Storme, L. Impact of skin-to-skin contact on the autonomic nervous system in the preterm infant and his mother. Infant Behav. Dev. 2017, 49, 83-86. [CrossRef] 
39. McCain, G.C.; Ludington-Hoe, S.M.; Swinth, J.Y.; Hadeed, A.J. Heart rate variability responses of a preterm infant to kangaroo care. J. Obstet. Gynecol. Neonatal. Nurs. JOGNN 2005, 34, 689-694. [CrossRef] [PubMed]

40. Haraldsdottir, K.; Watson, A.M.; Goss, K.N.; Beshish, A.G.; Pegelow, D.F.; Palta, M.; Tetri, L.H.; Barton, G.P.; Brix, M.D.; Centanni, R.M.; et al. Impaired autonomic function in adolescents born preterm. Physiol. Rep. 2018, 6, e13620. [CrossRef] [PubMed]

41. Patural, H.; Barthelemy, J.C.; Pichot, V.; Mazzocchi, C.; Teyssier, G.; Damon, G.; Roche, F. Birth prematurity determines prolonged autonomic nervous system immaturity. Clin. Auton. Res. 2004, 14, 391-395. [CrossRef] [PubMed]

42. Porges, S.W.; Furman, S.A. The early development of the autonomic nervous system provides a neural platform for social behaviour: A polyvagal perspective. Infant Child Dev. 2011, 20, 106-118. [CrossRef]

43. Mulkey, S.B.; du Plessis, A.J. Autonomic nervous system development and its impact on neuropsychiatric outcome. Pediatr. Res. 2019, 85, 120-126. [CrossRef]

44. Feldman, R.; Rosenthal, Z.; Eidelman, A.I. Maternal-preterm skin-to-skin contact enhances child physiologic organization and cognitive control across the first 10 years of life. Biol. Psychiatry 2014, 75, 56-64. [CrossRef]

45. Billman, G. The LF/HF ratio does not accurately measure cardiac sympatho-vagal balance. Front. Physiol. 2013, 4, 26. [CrossRef] [PubMed]

46. De Rogalski Landrot, I.; Roche, F.; Pichot, V.; Teyssier, G.; Gaspoz, J.-M.; Barthelemy, J.-C.; Patural, H. Autonomic nervous system activity in premature and full-term infants from theoretical term to 7 years. Auton. Neurosci. 2007, 136, 105-109. [CrossRef] [PubMed]

47. Julian, L.J. Measures of anxiety: State-Trait Anxiety Inventory (STAI), Beck Anxiety Inventory (BAI), and Hospital Anxiety and Depression Scale-Anxiety (HADS-A). Arthritis Care Res. 2011, 63, S467-S472. [CrossRef] [PubMed]

48. Hanson-Abromeit, D.; Shoemark, H.; Loewy, J. Music therapy with pediatric units: Newborn intensive care unit (NICU). In Medical Music Therapy for Pediatrics in Hospital Settings. Using Music to Support Medical Interventions; Hanson-Abromeit, D., Ed.; American Music Therapy Association: Silver Spring, MD, USA, 2008; pp. 15-69.

49. Roué, J.-M.; Kuhn, P.; Lopez Maestro, M.; Maastrup, R.A.; Mitanchez, D.; Westrup, B.; Sizun, J. Eight principles for patient-centred and family-centred care for newborns in the neonatal intensive care unit. Arch. Dis. Child. -Fetal Neonatal Ed. 2017, 102, F364-F368. [CrossRef] [PubMed]

50. Cong, X.; Ludington-Hoe, S.M.; McCain, G.; Fu, P. Kangaroo Care modifies preterm infant heart rate variability in response to heel stick pain: Pilot study. Early Hum. Dev. 2009, 85, 561-567. [CrossRef]

51. Gardner, F.C.; Adkins, C.S.; Hart, S.E.; Travagli, R.A.; Doheny, K.K. Preterm Stress Behaviors, Autonomic Indices, and Maternal Perceptions of Infant Colic. Adv. Neonatal. Care 2018, 18, 49-57. [CrossRef]

52. Thayer, J.F.; Lane, R.D. Claude Bernard and the heart-brain connection: Further elaboration of a model of neurovisceral integration. Neurosci. Biobehav. Rev. 2009, 33, 81-88. [CrossRef] 